\section{Dermohypodermite nécrosante}

\section{Necrotizing cellulitis}

\section{T. Sturiale}

Reçu le 12 décembre 2012 ; accepté le 22 février 2013

(C) SFMU et Springer-Verlag France 2013

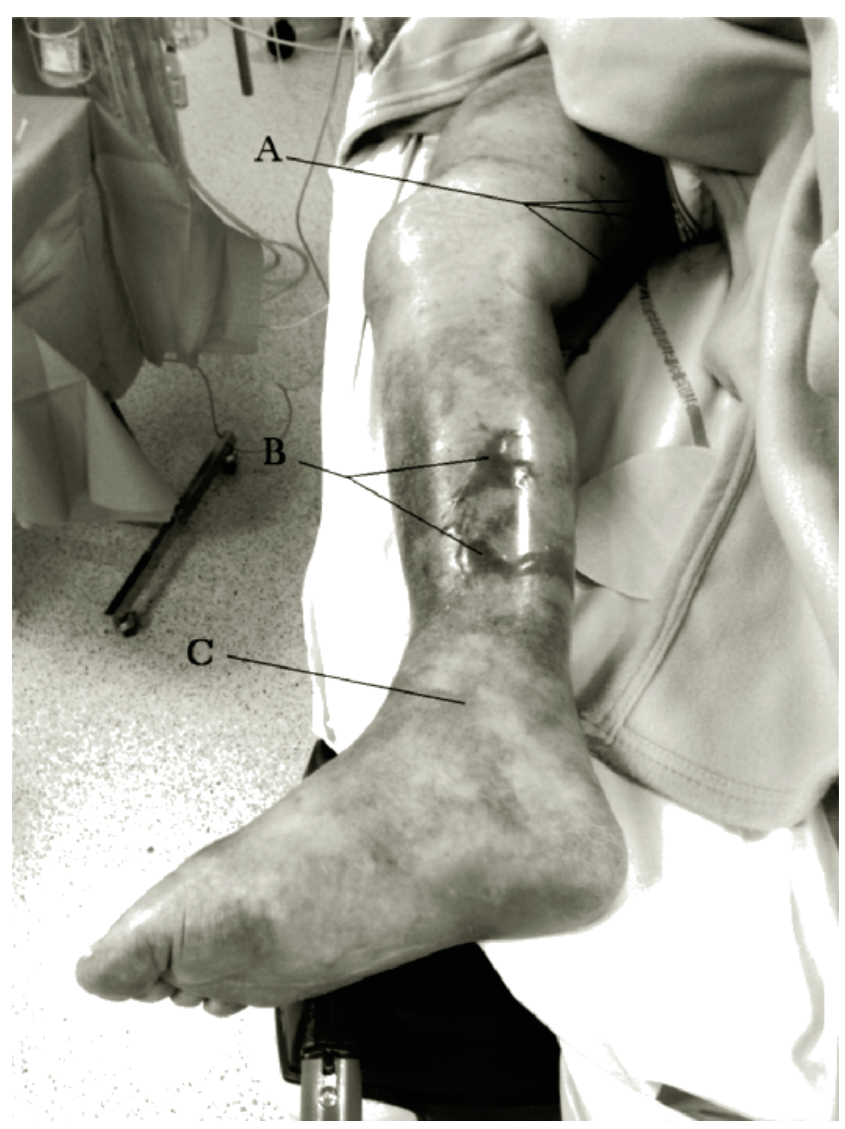

Fig. 1 Dermohypodermite nécrosante chez un patient de 67 ans. [A] tâches cyaniques, [B] bulles, [C] aspect livedoïde

T. Sturiale $(\bowtie)$

Service d'accueil des urgences, CHU « Le Bocage » Dijon,

F-21000 Dijon, France

e-mail : teddysturiale@gmail.com
Cette photographie d'une dermo-hypodermite nécrosante (Fig. 1) permet d'insister sur les différents signes cliniques locorégionaux qui traduisent la nécrose débutante (douleur croissante, œdème induré diffus, hypoesthésie, caractère purpurique et/ou bulleux, aspect livedoïde, tâches cyaniques).

Les dermohypodermites et fasciites nécrosantes font parties des urgences infectieuses auxquelles l'urgentiste peutêtre confronté, et pour lesquelles il existe une corrélation entre précocité du diagnostic et l'amélioration du pronostic [1].

\section{Référence}

1. Société de pathologie infectieuse de langue française, Société française de dermatologie. (2000) Conférence de consensus. Erysipèle et fasciite nécrosante : prise en charge. Med Mal Infect 30:245-6 